\title{
Race-Based Job Discrimination, Disparities in Job Control, and Their Joint Effects on Health
}

\author{
John D Meyer, MD, MPH ${ }^{1,2 *}$
}

\begin{abstract}
Objectives To examine disparities between job control scores in Black and White subjects and attempt to discern whether self-rated low job control in Blacks may arise from structural segregation into different jobs, or represents individual responses to race-based discrimination in hiring or promotion.

Methods Data from the National Survey of Midlife in the United States (MIDUS) were analyzed by mixed-effects linear regression and variance regression to determine the effects of grouping by occupation, and racial discrimination in hiring or promotion, on control scores from the Job Content Questionnaire in Black and White subjects. Path analyses were constructed to determine the mediating effect of discrimination on pathways from education and job control to self-rated health.

Results Black subjects exhibited lower mean job control scores compared to Whites (mean score difference 2.26, $P<0.001)$ adjusted for age, sex, education, and income. This difference narrowed to 1.86 when adjusted for clustering by occupation, and was greatly reduced by conditioning on race-based discrimination (score difference 1.03, $P=0.12$ ). Path analyses showed greater reported discrimination in Blacks with increasing education, and a stronger effect of job control on health in Black subjects.

Conclusions Individual racially-based discrimination appears a stronger determinant than structural segregation in reduced job control in Black workers, and may contribute to health disparities consequent on work. Am. J. Ind. Med. 57:587-595, 2014. () 2013 Wiley Periodicals, Inc.
\end{abstract}

KEY WORDS: job control; job discrimination; work psychosocial environment; racial disparities in health; occupational disparities

\section{INTRODUCTION}

With education and income, occupation is one of the main socioeconomic determinants of health [Schwartz

\footnotetext{
${ }^{1}$ Department of Environmental and Occupational Health Sciences, SUNY-Downstate School of Public Health, Brooklyn, New York

${ }^{2}$ Divison of Occupational and Environmental Medicine, Department of Preventive Medicine, Mount Sinai School of Medicine, New York, New York

Disclosure Statement: The author has no conflicts of interest to declare.

${ }^{*}$ Correspondence to: John D Meyer, MD, MPH, Environmental and Occupational Health Sciences, SUNY-Downstate School of Public Health, 450 Clarkson Ave Box 43, Brooklyn, NY11203.E-mail:john.meyer@downstate.edu
}

Accepted 22 August 2013

DOI 10.1002/ajim.22255. Published online 16 September 2013 in Wiley Online Library (wileyonlinelibrary.com). et al., 1988; Muntaner and Schoenbach, 1994; Savitz et al., 1996; Davey Smith et al., 1998; Karasek et al., 1998; Muntaner et al., 1998; de Jonge et al., 2000; Peter and Siegrist, 2000; Zimmerman et al., 2004; Brand et al., 2007; Meyer and Mutambudzi, 2012]. Occupations differ in rewards (both financial and non-monetary), societal prestige, authority, and independence, but also in level of physical application, stress, and exposure to harmful substances. These attributes may cluster in particular occupations; a mechanism whereby work contributes to differentials in health outcomes [MacDonald et al., 2001; Quinn et al., 2007]. The associations of job strain — high work demands coupled with low control over its conditions, originally posited by Karasek and colleagues - on a variety of health endpoints including hypertension, heart disease, and low birth weight, have been well described [Landsbergis 
et al., 1994; Karasek, 1996; Brett et al., 1997; Bosma et al., 1998; Peter and Siegrist, 2000; de Lange et al., 2003; Kuper and Marmot, 2003; Landsbergis et al., 2003; Ostry et al., 2004; Greenlund et al., 2010]. Our prior work indicates that low decision authority and skill discretion in work, traditionally operationalized as job control, may be a better predictor of adverse outcomes than job demands or the overall demand-control model [Meyer et al., 2010, 2011].

Less clear has been the role that job characteristics may play in racial and ethnic health disparities. Chung-Bridges et al. [2008] found that overrepresentation of Black workers in particular jobs was associated with poorer health in all who were employed within that occupation, irrespective of race. This suggests that, analogous to residential segregation, the consequences of occupational segregation may be deleterious to all workers. Whether the effect is mediated though environmental exposures, psychosocial hazards, reduced incomes, or a combination of these with other factors is not clear, however. Focusing on work's psychosocial hazards, we have found, when worker race/ethnicity is considered in stratified analyses of job characteristics and health outcomes, a pattern emerges of both lower job control and a greater effect of low job control on health in Black subjects [Brett et al., 1997; Thomas et al., 2004; Quinn et al., 2007; Meyer et al., 2010; Hurtado et al., 2012]. In addition, within equivalent educational strata, there are differences in the proportions of Blacks and Whites working in low-control occupations. We noted this differential in Black-White job control scores in two large nationally representative datasets, the National Longitudinal Survey of Youth [Meyer et al., 2010], where job control scores were imputed to subjects' occupation, and the National Survey of Midlife in the United States (MIDUS) [Meyer et al., 2011], where participants answered the Job Content Questionnaire as part of the survey. These findings suggest that adverse health outcomes, associated with low-control work in AfricanAmericans, are amplified by overrepresentation of Black subjects in these jobs which are incommensurate with their educational attainment.

Further assessment of these findings appears warranted. A search for determinants of differences in perceived job control may inform efforts at reducing health disparities arising from occupation. One salient question is whether lower self-rated job control in Blacks is a consequence of structural segregation into different jobs, or instead represents an individual response to acts of race-based discrimination in hiring or promotion. Although these two potential explanatory sources may not be mutually exclusive, they present a contrast between societal- versus individually-based discrimination, as inquiry into neighborhood residential segregation and similar population-level exposures have provided additional explanatory power for health disparities over and above individual-level risk factors [Subramanian et al., 2006; Krieger et al., 1997, 2003; Williams et al., 1997]. Structural segregation posits that differences in racial composition within jobs would be the consequence of broader societal factors operating in the occupational realm; these factors might include long-term traditional hiring practices, spatial segregation (mismatch between available jobs and worker residence), and discriminatory trade-union membership policies [Cutler and Glaeser, 1997; Nazroo and Williams, 2005; Chung-Bridges et al., 2008]. Support for structural segregation as a contributor to jobcontrol differences would be obtained if - given an overall disparity in mean job control scores-within-job control ratings are similar between Black and White workers. This finding would then imply that the discrepancy stems from overrepresentation of Blacks in work generally considered lacking in job authority or skill discretion [Karasek and Theorell, 1990; Karasek et al., 1998; MacDonald et al., 2001]. By contrast, support for the influence of individual responses to racial discrimination would be reflected by within- and between-job control score differences that narrow when conditioned on personal experiences of race-based discrimination. An ability to discern between the two potential explanations may have consequences in the design of work and work opportunities that reduce disparities in the work psychosocial environment, and lead to a reduction in morbidity associated with work.

In this study, the National Survey of Midlife in the United States (MIDUS), a large national survey with two waves, is used to examine the differences in job control scores in Black and White subjects which were noted previously. The conceptual framework outline above is applied to the analysis of job control to help determine an explanatory mechanism. Finally a set of path analyses for Black and White participants are constructed to examine whether pathways to self-rated health differ as a consequence by race, and whether these pathways differ, possibly through race-based discrimination, in the relative contributions of education and work, to participants' health.

\section{METHODS}

\section{Data Sources}

Survey data from the National Survey of Midlife in the United States (MIDUS) were obtained and used for the analyses in this investigation. The original MIDUS survey was a study of American adults aged 25-74, initiated by the MacArthur Midlife Research Network and designed to investigate social, behavioral, and psychological factors and their association with age-related changes in health. Respondents in the initial 1994/5 survey included a core sample $(\mathrm{N}=3,485)$, metropolitan over-samples (757), twins (998 pairs), and siblings (951) of core respondents. The 
second wave of the survey was initiated in 2005 and was designed to assess longitudinal changes in health, occupation, attitudes, and other important attributes of aging. Subject retention across the two waves of the study was in excess of $75 \%$. Sampling weights correcting for selection probability and non-response were calculated in the core sample only, and provided to match the core survey population to the age, sex, race, and educational profile of the US population. Subjects' work is categorized in both surveys by three-digit occupational and industry codes used for the 1990 census. MIDUS I and II survey data are de-identified and publically available from the Inter-University Consortium for Political and Social Research (ICPSR) at the University of Michigan [Brim et al., 1999; Ryff et al., 2007].

\section{Variables and Measures \\ Dependent/outcome measures}

Job demand-control characterization. Both waves of MIDUS include questions drawn from the job content questionnaire (JCQ) [Karasek et al., 1998] assessing job demands (5 items), skill discretion (6 items), and decision authority ( 3 items). The latter two compose the overall 9-item construct termed job control. Items in MIDUS were answered on a 5-point response scale, and were reverse-coded for this analysis, so that higher scores represented higher control levels, as in standard JCQ scoring, and aggregated according to the methods of Schwartz et al. [1988], Karasek et al. [1998]. Individual items were also assessed for internal consistency using confirmatory factor analysis and Chronbach's alpha, as we previously described [Meyer et al., 2011].

Self-rated physical health was assessed by MIDUS participants in each wave of the survey on a scale from one (poor) to five (excellent). Health ratings from the 2005 survey were used as an ordinal response variable in path analyses to evaluate the association of job control and education with health, and describe potential mediation of this pathway by job discrimination.

\section{Independent Variables}

Demographics. Data on participants' age, sex, race and country of family origin, educational attainment, and household income were collected in the MIDUS surveys. Data on participants was included in these analyses if they self-identified as either White or Black/African-American; this excluded those identifying as Asian/Pacific Islander, Native American, "Mixed," and "Other." Educational attainment in the MIDUS surveys is categorized as an ordinal variable with discrete categories corresponding to usual metrics of educational attainment (non-high-school graduate, high-school graduate, some college, college graduate, or further). Data on total household income included participants' own wages and earnings, spousal income, unemployment benefits, and income to the household from pensions and other sources, in 1995 dollars.

\section{Other independent variables}

Occupational data collected in the 1994-1995 survey was coded according to 1990 census standard occupation and industry codes. Variables for perceived job discrimination by race were constructed from two sets of discrimination questions in the MIDUS survey. Answers to two questions (requesting the number of times "You were not hired for a job" or "You were not given a promotion") out of eleven inquiring into possible domains of discrimination were matched with participants' assessment of whether discrimination had occurred based on race or ethnicity (and distinguished, e.g., from that based on sex, age, or disability) [Williams et al., 1997]. Answers were dichotomized based on an affirmative answer to the racial-discrimination question and cross-tabulated with each of the job-discrimination questions. A three point scale describing whether subjects had experienced: (a) neither, (b) one, or (c) both race-based hiring or promotion discrimination was then constructed from these two cross-tabulations, and used in the analyses.

The MIDUS questionnaire used the mean of six item responses to score negative affectivity, a construct derived from the Center for Epidemiologic Studies Depression (CESD) scale that may indicate a tendency to view events and features of one's life in an adverse light [Mroczek and Kolarz, 1998]. The negative affectivity scale was used in the analyses to control for potential confounding whereby participants may rate both working conditions and health pessimistically as part of a more generalized psychological profile.

From the 1995 core MIDUS sample of 7,108, and excluding non-Black non-White subjects, a total of 3,841 participants (54\%) had complete data on occupation, work demand and control scores from the JCQ, education, and assessment of discrimination in hiring or promotion. Of this 1995 sample, 2,907 (75.7\%) were surveyed in 2005 and provided data on self-rated health.

\section{Analytic Strategy}

Analyses were performed using STATA v.11 (StataCorp, College Station, TX). Path analyses were performed in MPlus v.6.0 (Muthén and Muthén, Los Angeles, CA). Occupational and demographic variables were tabulated and examined (Table I). Differences in Black/White job control scores were analyzed by mixed-effects linear regression using command 
TABLE I. Demographic Characteristics of Study Participants. MIDUS Survey1994-1995

\begin{tabular}{lccc} 
& $\begin{array}{c}\text { White } \\
\text { (3,652) }\end{array}$ & $\begin{array}{c}\text { Black } \\
(\mathbf{1 8 9 )}\end{array}$ & Significance \\
\hline Age, mean, years (SD) & $44.5(11.1)$ & $42.4(11.0)$ & NS \\
Female, number (\%) & $1738(47.6 \%)$ & $109(57.7 \%)$ & $P=0.02$ \\
Education, median, years (SD) & $15(2.4)$ & $14(2.6)$ & $P=0.04$ \\
Household income \$, median, (SD) & 64,500 & 42,500 & $P=0.003$ \\
& $(62,802)$ & $(54,356)$ & \\
Job demands: mean JCQ score (SD) & $13.9(2.3)$ & $15.0(3.1)$ & $P=0.04$ \\
Job control: mean JCQ score (SD) & $33.3(6.0)$ & $30.4(7.4)$ & $P=0.0004$ \\
Negative affectivity, mean CES-D & $1.52(0.7)$ & $1.60(1.1)$ & NS \\
$\quad$ scale score (SD) & & & \\
Denied promotion or job on basis of race: Number (\%) & \\
Neither & 3379 & 88 & $P<0.001$ \\
Either promotion or job & $98(2.7)$ & $39(20.6)$ & \\
Both & $44(1.2)$ & $39(20.6)$ & \\
Missing & $131(3.6)$ & $23(12.2)$ & \\
Major industry classification: Top 5 industries(\%) & & \\
Professional and related services & $790(21.6)$ & $38(20.1)$ & NS \\
Manufacturing industries & $587(16.1)$ & $29(15.3)$ & \\
Trade (retail and wholesale) & $572(15.7)$ & $23(12.2)$ & \\
Educational services & $367(10.0)$ & $29(15.3)$ & \\
Health services & $345(9.4)$ & $23(12.2)$ & \\
Self-rated health (MIDUS 2005 survey): Number (\%) & & \\
Poor & $77(2.7 \%)$ & $1(0.9 \%)$ & NS \\
Fair & $235(8.3)$ & $8(8.3)$ & \\
Good & $796(28.2)$ & $34(39.4)$ & \\
Very good & $1151(40.8)$ & $29(35.8)$ & \\
Excellent & $562(19.9)$ & $14(15.6)$ & \\
\hline & & & \\
\hline
\end{tabular}

Statistical significance calculated by two-tailed chi-squared or $t$-tests. NS, not statistically significant at 0.05 level.

syntax xtmixed in STATA. The general model for these analyses can be expressed as:

$$
\begin{aligned}
y_{i j}= & \beta_{0}+\beta_{O C C} X_{O C C i j}+\sum \beta_{h} X_{h i}+\left(u_{0 j}+u_{O C C} X_{O C C i j}\right. \\
& \left.+e_{0 i j}\right)
\end{aligned}
$$

where $\beta_{0}$ represents the model intercept, $\beta_{\text {OCC }}$ a level-2 random coefficient for nesting of individuals $i$ in jobs $j$, and $\beta_{h}$ a set of $h$ coefficients for a vector of fixed level-1 variables (age, sex, education, income, negative affectivity, and discrimination) included in the model, with level-1 and -2 error terms in the brackets. An initial "naïve" model adjusted for age, sex, education, and household income was first created. Subjects' occupation was next included as a random level-2 variable, followed by inclusion of a cross-level interaction term for occupation by race (in the model's notation: $\mathrm{x}_{\mathrm{OCCij}} \times \mathrm{x}_{\text {race }}$ ) to evaluate the possibility that differential nesting of subjects within occupations accounted for the observed differences in job control scores. These two models were designed to assess structural segregation as an explanation for the discrepancy in job control between Black and White participants seen in the naïve model. In a final model, the variable indicating individual-level experience of discrimination (in hiring, promotion, or both) was added as a covariate. This was intended, by contrast with the inclusion of occupation, to assess the contribution of person-level, as distinct from structural, discrimination. Scores for negative affectivity were also included in a parallel set of models to examine the possibility of response- or common-instrument bias, and to determine whether job discrimination might covary with other negative survey responses.

In addition to examining between-group racial/ethnic differences in job control, a variance function regression model was introduced to evaluate within-group heterogeneity in the population sample and changes in the residual variance of the linear mixed regression model as relevant covariates are added. Methods are outlined by Western and Bloome [2009] and entail an iterative set of gamma regressions (using a log link) of the squared residuals from each linear regression model on the covariates that were included in the model. The resultant coefficient describes the degree to which withingroup (as opposed to between-group) heterogeneity contributes to inequality, and assists in discerning or discovering omitted variables, or the influence of an included factor. For ease of interpretation, the coefficients are exponentiated and interpreted as odds ratios (ORs); thus a logistic coefficient value close to 0 (representing an OR close to 1) indicates a reduction in residual variance and thus a low degree of heterogeneity amongst subjects, while an OR deviating further from the null suggests greater heterogeneity and consideration that additional explanatory variables be added to the model.

Path analyses were constructed in Mplus v.6 and used to describe the association of educational attainment, job control, and the potential mediating effect of racial job discrimination on the participants' self rated health at the time of the second MIDUS survey 10 years later. We assumed a priori that participants' self-identified race preceded both educational attainment and job control, and that education likewise preceded job control. Self-rated health from the second survey was used to ensure the temporal ordering of exposure and outcome, and was further conditioned on participants' self-rated health from the first (1995) survey. Aside from these fixed specifications, the building of path models tested alternative direct and indirect pathways and associations of these variables with later health. Path models were tested by using: (a) the root mean square error of approximation (RMSEA) as a guide to overall goodness-offit of the model, with a general criterion of a RMSEA value of $\leq 0.05$ indicating good model fit; (b) a $P$ value of $\leq 0.1$ as a guide to the significance of individual paths within the model; 
and (c) the scaled $\chi^{2}$ difference test (using the DIFFTEST procedure in MPlus), to examine whether inclusion or exclusion of a specified pathway resulted in a statistically significant change in the model's overall fit. Path model results are reported as standardized coefficients to facilitate comparisons of their magnitude.

Approval for this study was obtained from the Institutional Review Board of the University of Connecticut Health Center, which judged the investigation as exempt from human subjects review, as all data were previously deidentified and made publically available.

\section{RESULTS}

Of the set of 3,841 MIDUS participants used in the analyses, 3,652 were identified as White and $189(5 \%)$ as Black (the Milwaukee African-American MIDUS sub-study was performed only in the MIDUS II (2005) study, did not include the JCQ, and therefore could not be included in these analyses). Demographic characteristics and study variables for the overall sample, as well as for Black subjects alone are shown in Table I. Black participants were not significantly different from Whites in age, negative affectivity score, and the distribution of self-rated health in the 2005 survey. Significant differences were noted in job control scores, household income sex composition and the extent to which subjects had experienced hiring or promotion discrimination based on race (a total of $41.2 \%$ in Blacks experienced one or both, vs. 3.9\% for Whites), and to a lesser extent in educational attainment and job demands score. Distribution of Black participants' work by industrial sector was similar to the overall distribution of work, although Blacks were proportionately better represented in education and health services.

Table II outlines the analyses of White-Black differences in job control scores using a mixed-effects regression model. Model 1 represents a naïve ANCOVA analysis in which control scores are adjusted for relevant covariates (age, sex, education, and income) and shows a lower mean adjusted control score for Black subjects contrasted with Whites (difference of 2.26, $P<0.001$ ). This difference was partially attenuated (to $1.87, P<0.001$ ) by introduction of subjects' occupation as a random effect, which accounts for potential differences in clustering of subjects within occupation. The variance coefficient for this model increased slightly (OR $=1.45$ ), indicating persisting heterogeneity within the subject panel despite adjustment for the job mix of subjects. Inclusion of a cross-level interaction term (occupation $\times$ race; Model 3) to account for possible differential job clustering between Black and White subjects did not alter the observed mean job control differences, although it modestly reduced the variance regression coefficient $(\mathrm{OR}=1.27)$. Finally, addition of the individual-level measure of job discrimination in hiring or promotion, as shown in Model 4, substantially

TABLE II. Differences in Mean Job Control Score, Contrast between White and Black Subjects; MIDUS1995 Survey

\begin{tabular}{|c|c|c|c|c|c|c|c|}
\hline & $\begin{array}{c}\text { Mean job } \\
\text { control } \\
\text { score: White }\end{array}$ & $\begin{array}{c}\text { Mean job } \\
\text { control } \\
\text { score: Black }\end{array}$ & Difference & $\begin{array}{l}\text { P for control } \\
\text { score } \\
\text { difference }\end{array}$ & $\begin{array}{l}\text { Variance } \\
\text { coefficient }\end{array}$ & $\begin{array}{l}\text { Variance } \\
\text { coefficient } \\
\text { (OR) }\end{array}$ & $\begin{array}{c}\text { Model fit } \\
\text { (-2 log likelihood) }\end{array}$ \\
\hline \multicolumn{8}{|l|}{ Model1 } \\
\hline $\begin{array}{l}\text { Job control by race, adjusted for age, } \\
\text { sex, educational attainment, income }\end{array}$ & 33.23 & 30.97 & 2.26 & $<0.001$ & 0.247 & 1.28 & 17,826 \\
\hline \multicolumn{8}{|l|}{ Model 2} \\
\hline $\begin{array}{l}\text { Model } 1 \text { with occupation included as a } \\
\text { random level-2 effect }\end{array}$ & 32.58 & 30.71 & 1.87 & 0.001 & 0.368 & 1.45 & 17,628 \\
\hline \multicolumn{8}{|l|}{ Model 3} \\
\hline $\begin{array}{l}\text { Model } 2 \text { with an occupation } \times \text { race } \\
\text { interaction term added }\end{array}$ & 32.58 & 30.76 & 1.82 & 0.002 & 0.236 & 1.27 & 17,627 \\
\hline \multicolumn{8}{|l|}{ Model 4} \\
\hline $\begin{array}{l}\text { Model } 3 \text { with individual job discrimination } \\
\text { measure included as covariate }\end{array}$ & 32.60 & 31.56 & 1.03 & 0.12 & -0.122 & 0.89 & 16,910 \\
\hline \multicolumn{8}{|l|}{ Model 5} \\
\hline $\begin{array}{l}\text { Model } 3 \text {, with negative affectivity included } \\
\text { as a covariate }\end{array}$ & 32.57 & 30.82 & 1.75 & 0.003 & 0.270 & 1.31 & 17,601 \\
\hline \multicolumn{8}{|l|}{ Model 6} \\
\hline $\begin{array}{l}\text { Model } 4 \text {, with negative affectivity included } \\
\text { as a covariate }\end{array}$ & 32.58 & 31.58 & 1.01 & 0.13 & 0.059 & 1.06 & 16,889 \\
\hline
\end{tabular}


reduced the control score differential between the two groups while shrinking the variance coefficient toward the null $(\mathrm{OR}=0.89 ; \quad P=0.68)$. To examine the possibility of response- or common-instrument bias, the same models were run with the inclusion of a score for negative affectivity; results are shown as Models 5 and 6. By contrast with the results of models using discrimination measures, inclusion of negative affectivity alone did not substantially reduce BlackWhite control score differences (Model 5), nor did joint inclusion of both measures affect the estimation of job control any further than did the job discrimination measure alone. This suggests that MIDUS subjects' assessments of raciallybased job discrimination were likely unaffected by a propensity toward more global negative responses in the survey.

Results of path analyses, using self-rated health in the 2005 survey as an outcome measure, are shown in Figure 1. Construction of a path model in White participants (Panel B) demonstrates a direct effect of education on health as the salient pathway (overall model RMSEA $=0.059$ ). A second pathway in which job control serves as an intervening variable is of low magnitude and statistically insignificant (path coefficient $=0.02 ; P=0.19$ ). Inclusion of a path leading from job discrimination to self-rated health yielded a small, marginally significant path coefficient $(-0.03$, $P=0.063$ ) which was included in the model. In contrast, the path analysis for Black subjects alone indicated strikingly different coefficients for the associations between education, discrimination, work, and health (Fig. 1, Panel A). The direct pathway coefficient from education to health was negligible $(-0.005)$ and not significant. Although shown in Panel A for completeness' sake, the direct path from education to health was excluded from the overall best-fitting path model (RMSEA $=0.01$, when education was excluded) represented by the path coefficients shown in Panel A. Black subjects also exhibited a much stronger association of job control with health (path coefficient $0.20 ; P=0.03$ for Blacks). Finally, the association of education with discrimination in Blacks

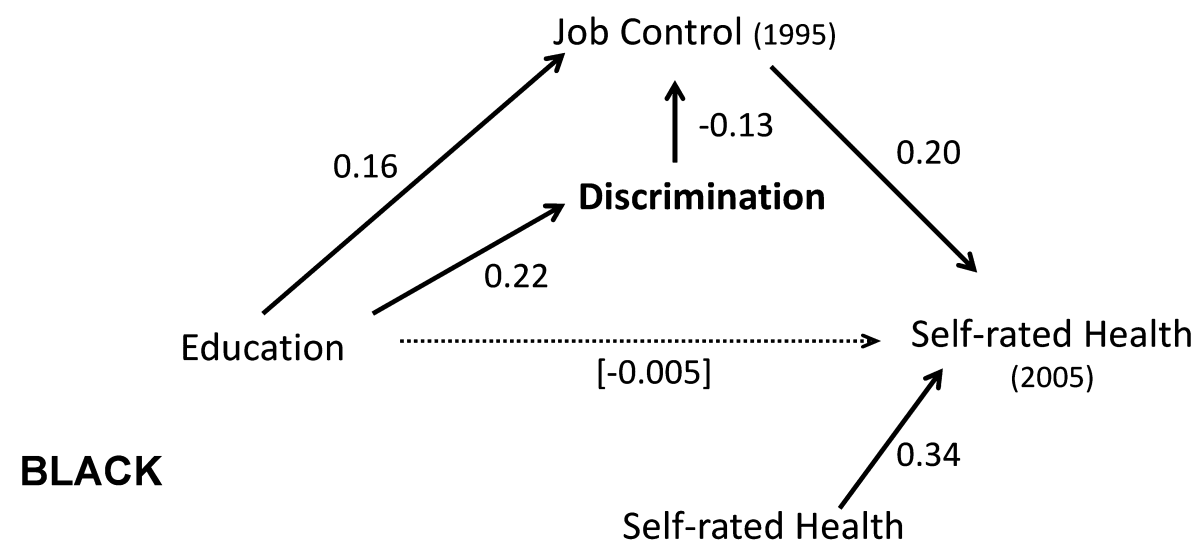

(1995)

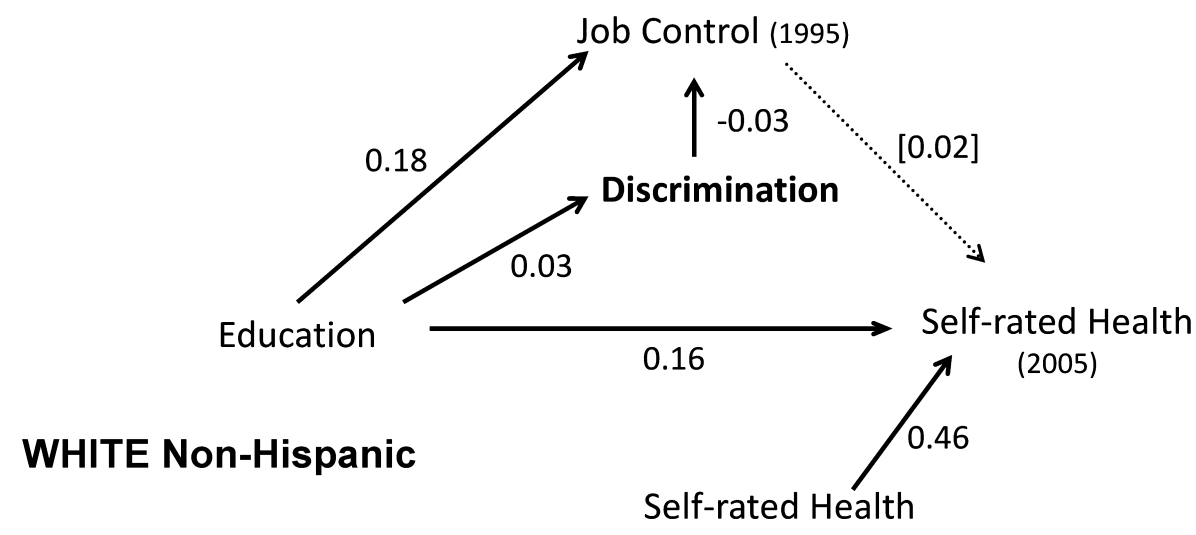

(1995)

FIGURE 1. Path analyses of contribution of education, 1995 job control, and job discrimination on self-rated health in 2005: Black (Panel A) and White (Panel B) participants. Figures are standardized path coefficients. 
was particularly noteworthy, the positive coefficient $(0.22$; $P=0.005)$ indicating that job-based racial discrimination was greater with increased education.

\section{DISCUSSION}

Disparities in the workplace psychosocial environment, including low job control and high job strain, have previously been reported and are generally found to be greater in Black subjects when contrasted with Whites or Latinos [Quinn et al., 2007; Meyer et al., 2011; Hurtado et al., 2012; Meyer and Mutambudzi, 2012]. While the effects of low job control and high strain, including hypertension, cardiovascular disease, and adverse pregnancy outcomes are well described [Karasek, 1996; Landsbergis and Hatch, 1996; de Lange et al., 2003; Landsbergis et al., 2003; Meyer et al., 2007; Smith et al., 2008a,b], the underlying reasons for disproportionately high adverse work exposures in Blacks has received less attention. Findings that high representation of AfricanAmericans within a particular occupation affected the health of all workers within that job suggest the possibility of structural segregation as a determinant of ill-health [ChungBridges et al., 2008]. By contrast, a study of older workers found little association of hypertension with job strain and workplace discrimination in African-American or Hispanic workers, indicating to the investigators that resilience may develop to work-related stressors [Mezuk et al., 2011] but which contradicts the evidence for high-effort coping, or "John Henryism," at work as a contributor to hypertension and poor health [James et al., 1984]. Efforts at discerning the origin and extent of workplace stressors are complicated by factors such as educational attainment [Miech and Hauser, 2001; Singh-Manoux et al., 2002; Farmer and Ferraro, 2005; Brand et al., 2007; Meyer et al., 2010], other indicators of social class or prestige [Davey Smith et al., 1998; Warren and Kuo, 2003; Warren et al., 2004], employment relations [Muntaner et al., 2010], and intergenerational SES [Foster et al., 2000; Astone et al., 2007].

The multilevel analytic results presented in Table II suggest that the differences in observed self-rated job control arise from both individual experiences of job discrimination and systematic segregation of subjects into work with fewer opportunities for skill discretion or decision authority, although the former appears to be a stronger determinant of job control. Accounting for structural discrimination (systematic differences in channeling subjects into, or away from, specific occupations) by the inclusion of occupation as a random factor in the mixed regression model changed the estimation of differences in self-assessed job control. As indicated by the high variance coefficient, persistent heterogeneity within the dataset (inter-group differences) remained high, suggesting structural segregation was not the sole, or even stronger determinant of differences in control. By contrast, both job control and the overall residual variance are markedly reduced by addition of the individual-level discrimination variable. While these models cannot exclude the possibility of a broader macroeconomic-level discrimination [Chung-Bridges et al., 2008], the weighting strategy of the MIDUS survey is designed to account for selection probability and subject non-response. A separate analysis of only the core MIDUS sample, using survey weights, shows essentially the same findings, in magnitude and direction (results not shown), thereby suggesting these analyses are less likely to reflect selection bias. The findings of differences in job control were robust to other possible job-related covariates, including income and education. A possible reason for this finding may be that differences in task-level job factors are not adequately represented by occupational title, but are specific to individuals within socially-structured jobs. Differences in sex-typed job exposures within equivalent job titles have been recognized and described as possible causes of gender differences in the health effects of psychosocial work factors [Messing et al., 1993, 1994]. As these results, as well as other recent studies [Hurtado et al., 2012] suggest similar possibilities in different racial and ethnic groups, additional investigation into the relevant pathways seems warranted. As an additional control on the possibility of common-instrument bias, or a tendency to more uniformly downgrade ones' answers, scores for the negative affectivity component of the CES-D were incorporated into the analyses; these showed no additional, equivalent, or additive effect on the mean job control scores than did use of discrimination variables, suggesting that participants' assessment of job control and discrimination was unaffected by individual psychological factors.

Two distinct pathways from education and job control to overall health are apparent in Figure 1. The direct education-tohealth pathway is essentially absent in Black subjects. Moreover, the extent to which increased education is correlated with increased discrimination and hence reduced job control given educational attainment is striking. A fivefold difference is apparent between Black and White participants. While the health effects of racial discrimination have been well-described [Curtis et al., 1997; Williams et al., 1997; DinDzietham et al., 2004; Hurtado et al., 2012], this pathway appears to obviate the effect of education on health entirely in Blacks, and thus may provide at least a partial explanation for decreasing returns in health from increased education that have been described in African-Americans for over two decades [McGrady et al., 1992; Collins and Butler, 1997; Collins et al., 2004; Farmer and Ferraro, 2005; Meyer et al., 2010].

The results presented here have some limitations. The possibility of differential survey sampling has been mentioned above. Designation of participants as Black/AfricanAmerican or White is straightforwardly made by the MIDUS survey; however, specifying subjects as Hispanic or Latino requires an investigator to make assumptions about a combination of self-designated ethnicity and country of 
origin, which was not done here. Evidence suggests a very different set of education and work pathways for Hispanic individuals, which may differ further between immigrants and US-born persons [Franzini et al., 2001; Turra and Goldman, 2007]. The lack of a questionnaire-based metric for assessing physical demands in the survey participants excludes a potentially important occupational factor affecting health. Covariation has been noted between scores for job control and psychological demands and those for work's physical demands, which suggests that these constructs may arise from more fundamental workplace organizational factors [MacDonald et al., 2001]. Although other investigations have noted that associations between job control and health outcomes remain robust to the inclusion of workplace physical factors [Meyer et al., 2007], the probability that high-control work may represent work that is low in deleterious physical demands or hazards should not be overlooked. A second limitation is the possibility of differential losses to follow-up between the first and second surveys, which may bias results if either non-participation or retirement by the time of the second survey is based on participants' work characteristics or conditions. However, in a previous paper, job characteristics were analyzed in MIDUS responders versus non-responders between the two surveys: we found little significant difference in job control between the two groups [Meyer et al., 2011].

In conclusion, self-rated job control was found to be lower in African-American/Black subjects than in Whites in the MIDUS survey, which attempts to represent a broad swathe of the US working population at mid-career and later. The difference appears to be more strongly associated with a history of individual job-based discrimination, either in hiring or promotion, than structural discrimination differentially placing subjects into jobs, although both may be operating. The effect of this discrimination appears to be higher in bettereducated Black subjects. Its consequences may be that the direct pathway from education to better health is blocked or obviated in Black workers. Additional investigation as to the mechanisms by which this differential action of education, discrimination, and work act upon health seems warranted.

\section{REFERENCES}

Astone NM, Misra D, Lynch C. 2007. The effect of maternal socioeconomic status throughout the lifespan on infant birthweight. Paediatr Perinat Epidemiol 21:310-318.

Bosma H, Peter R, Siegrist J, Marmot M. 1998. Two alternative job stress models and the risk of coronary heart disease. Am J Public Health 88:68-74.

Brand JE, Warren JR, Carayon P, Hoonakker P. 2007. Do job characteristics mediate the relationship between SES and health? Evidence from sibling models. Soc Sci Res 36:222-253.

Brett KM, Strogatz DS, Savitz DA. 1997. Employment, job strain, and preterm delivery among women in North Carolina. Am J Public Health 87:199-204.
Brim OG, Baltes PB, Bumpass LL, Cleary PD, Featherman DL, Hazzard WR, Kessler RC, Lachman ME, Markus HR, Marmot MG, Rossi AS, Ryff CD, Shweder RA. 1999. National Survey of Midlife Development in the United States (MIDUS), 1995-1996. Ann Arbor, MI: Interuniversity Consortium for Political and Social Research,

Chung-Bridges K, Muntaner C, Fleming LE, Lee DJ, Arheart KL, LeBlanc WG, Christ SL, McCollister KE, Caban AJ, Davila EP. 2008. Occupational segregation as a determinant of US worker health. Am J Ind Med 51:555-567.

Collins JW, Jr. Butler AG. 1997. Racial differences in the prevalence of small-for-dates infants among college-educated women. Epidemiology $8: 315-317$.

Collins JW, Jr. David RJ, Handler A, Wall S, Andes S. 2004. Very low birthweight in African American infants: The role of maternal exposure to interpersonal racial discrimination. Am J Public Health 94:21322138

Curtis AB, James SA, Raghunathan TE, Alcser KH. 1997. Job strain and blood pressure in African Americans: The Pitt County Study. Am J Public Health 87:1297-1302.

Cutler DM, Glaeser EL. 1997. Are ghettos good or bad? Q J Econ 112:827-872.

Davey Smith G, Hart C, Hole D, MacKinnon P, Gillis C, Watt CG, et al. 1998. Education and occupational social class: Which is the more important indicator of mortality risk? J Epidemiol Community Health $52: 153-160$.

de Jonge J, Bosma H, Peter R, Siegrist J. 2000. Job strain, effort-reward imbalance and employee well-being: A large-scale cross-sectional study. Soc Sci Med 50:1317-1327.

de Lange AH, Taris TW, Kompier MA, Houtman IL, Bongers PM. 2003. "The very best of the millennium": Longitudinal research and the demand-control-(support) model. J Occup Health Psychol 8:282-305.

Din-Dzietham R, Nembhard WN, Collins R, Davis SK. 2004. Perceived stress following race-based discrimination at work is associated with hypertension in African-Americans. The metro Atlanta heart disease study, 1999-2001. Soc Sci Med 58:449-461.

Farmer MM, Ferraro KF. 2005. Are racial disparities in health conditional on socioeconomic status? Soc Sci Med 60:191-204.

Foster HW, Wu L, Bracken MB, Semenya K, Thomas J, Thomas J. 2000. Intergenerational effects of high socioeconomic status on low birthweight and preterm birth in African Americans. J Natl Med Assoc 92:213-221.

Franzini L, Ribble JC, Keddie AM. 2001. Understanding the Hispanic paradox. Ethn Dis 11:496-518.

Greenlund KJ, Kiefe CI, Giles WH, Liu K. 2010. Associations of job strain and occupation with subclinical atherosclerosis: The CARDIA Study. Ann Epidemiol 20:323-331.

Hurtado DA, Sabbath EL, Ertel KA, Buxton OM, Berkman LF. 2012. Racial disparities in job strain among American and immigrant longterm care workers. Int Nurs Rev 59:237-244.

James SA, LaCroix AZ, Kleinbaum DG, Strogatz DS. 1984. John Henryism and blood pressure differences among black men II. The role of occupational stressors. J Behav Med 7:259-275.

Karasek R. 1996. Job strain and the prevalence and outcome of coronary artery disease. Circulation 94:1140-1141.

Karasek R, Theorell T. 1990. Healthy work: Stress, productivity, and the reconstruction of working life. New York: Basic Books.

Karasek R, Brisson C, Kawakami N, Houtman I, Bongers P, Amick B. 1998. The job content questionnaire (JCQ): An instrument for internationally comparative assessments of psychosocial job characteristics. J Occup Health Psychol 3:322-355. 
Krieger N, Williams DR, Moss NE. 1997. Measuring social class in US public health research: Concepts, methodologies, and guidelines. Annu Rev Public Health 18:341-378.

Krieger N, Chen JT, Waterman PD, Rehkopf DH, Subramanian SV. 2003. Race/ethnicity, gender, and monitoring socioeconomic gradients in health: A comparison of area-based socioeconomic measures-the public health disparities geocoding project. Am J Public Health 93:1655-1671.

Kuper H, Marmot M, 2003. Job strain, job demands, decision latitude, and risk of coronary heart disease within the Whitehall II study. J Epidemiol Community Health 57:147-153.

Landsbergis P, Hatch MC. 1996. Psychosocial work stress and pregnancy-induced hypertension. Epidemiology 7:346-351.

Landsbergis PA, Schnall PL, Warren K, Pickering TG, Schwartz JE. 1994. Association between ambulatory blood pressure and alternative formulations of job strain. Scand J Work Environ Health 20:349-363

Landsbergis PA, Schnall PL, Pickering TG, Warren K, Schwartz JE. 2003. Life-course exposure to job strain and ambulatory blood pressure in men. Am J Epidemiol 157:998-1006.

MacDonald LA, Karasek RA, Punnett L, Scharf T. 2001. Covariation between workplace physical and psychosocial stressors: Evidence and implications for occupational health research and prevention. Ergonomics 44:696-718.

McGrady GA, Sung JF, Rowley DL, Hogue CJ. 1992. Preterm delivery and low birth weight among first-born infants of black and white college graduates. Am J Epidemiol 136:266-276.

Messing K, Doniol-Shaw G, Haentjens C. 1993. Sugar and spice and everything nice: Health effects of the sexual division of labor among train cleaners. Int J Health Serv 23:133-146.

Messing K, Dumais L, Courville J, Seifert AM, Boucher M. 1994. Evaluation of exposure data from men and women with the same job title. J Occup Med 36:913-917.

Meyer JD, Mutambudzi M. 2012. Construction of life-course occupational trajectories: Evidence for work as a mediator of racial disparities in hypertension. J Occup Environ Med 54:1201-1207.

Meyer JD, Warren N, Reisine S. 2007. Job control, substantive complexity, and risk for low birth weight and preterm delivery: An analysis from a state birth registry. Am J Ind Med 50:664-675.

Meyer JD, Warren N, Reisine S. 2010. Racial and ethnic disparities in low birth weight delivery associated with maternal occupational characteristics. Am J Ind Med 53:153-162.

Meyer JD, Cifuentes M, Warren N. 2011. Association of self-rated physical health and incident hypertension with $\mathrm{O}^{*} \mathrm{NET}$ factors: Validation using a representative national survey. J Occup Environ Med 53:139-145.

Mezuk B, Kershaw KN, Hudson D, Lim KA, Ratliff S. 2011. Job strain, workplace discrimination, and hypertension among older workers: The Health and Retirement Study. Race Soc Probl 3:38-50.

Miech RA, Hauser RM. 2001. Socioeconomic status and health at midlife. A comparison of educational attainment with occupation-based indicators. Ann Epidemiol 11:75-84.

Mroczek DK, Kolarz CM. 1998. The effect of age on positive and negative affect: A developmental perspective on happiness. J Pers Soc Psychol 75:1333-1349.

Muntaner C, Schoenbach C. 1994. Psychosocial work environment and health in U.S. metropolitan areas: A test of the demand-control and demand-control-support models. Int J Health Serv 24:337-353.

Muntaner C, Nieto FJ, Cooper L, Meyer J, Szklo M, Tyroler HA. 1998. Work organization and atherosclerosis: Findings from the ARIC study. Atherosclerosis risk in communities. Am J Prev Med 14:9-18.
Muntaner C, Borrell C, Vanroelen C, Chung H, Benach J, Kim IH, Ng E. 2010. Employment relations, social class and health: A review and analysis of conceptual and measurement alternatives. Soc Sci Med $71: 2130-2140$.

Nazroo J, Williams D. 2005. The social determination of ethnic/racial inequalities in health. In: Marmot MG, Wilkinson RG, editors. Social determinants of health. Oxford, New York: Oxford University Press. pp. $238-266$

Ostry AS, Hershler R, Chen L, Hertzman C. 2004. A longitudinal study comparing the effort-reward imbalance and demand-control models using objective measures of physician utilization. Scand J Public Health 32:456-463.

Peter R, Siegrist J. 2000. Psychosocial work environment and the risk of coronary heart disease. Int Arch Occup Environ Health 73(Suppl):S41-S45.

Quinn MM, Sembajwe G, Stoddard AM, Kriebel D, Krieger N, Sorensen G, Hartman C, Naishadham D, Barbeau EM. 2007. Social disparities in the burden of occupational exposures: Results of a crosssectional study. Am J Ind Med 50:861-875.

Ryff CD, Almeida DM, Ayanian JS, Carr DS, Cleary PD, Coe C, et al. Midlife Development in the United States (MIDUS2), 2004-2006 In. 2007-03-22 ed. Ann Arbor, Mich.: Inter-university Consortium for Political and Social Research [distributor]; 2007.

Savitz DA, Olshan AF, Gallagher K. 1996. Maternal occupation and pregnancy outcome. Epidemiology 7:269-274.

Schwartz JE, Pieper CF, Karasek RA. 1988. A procedure for linking psychosocial job characteristics data to health surveys. Am J Public Health 78:904-909.

Singh-Manoux A, Clarke P, Marmot M. 2002. Multiple measures of socio-economic position and psychosocial health: Proximal and distal measures. Int J Epidemiol 31:1192-1199, discussion 1199-1200.

Smith P, Frank J, Bondy S, Mustard C. 2008a. Do changes in job control predict differences in health status? Results from a longitudinal national survey of Canadians. Psychosom Med 70:85-91.

Smith PM, Frank JW, Mustard CA, Bondy SJ. 2008b. Examining the relationships between job control and health status: A path analysis approach. J Epidemiol Community Health 62:54-61.

Subramanian SV, Chen JT, Rehkopf DH, Waterman PD, Krieger N. 2006. Comparing individual- and area-based socioeconomic measures for the surveillance of health disparities: A multilevel analysis of Massachusetts births, 1989-1991. Am J Epidemiol 164:823-834.

Thomas KS, Nelesen RA, Ziegler MG, Bardwell WA, Dimsdale JE. 2004. Job strain, ethnicity, and sympathetic nervous system activity. Hypertension 44:891-896.

Turra CM, Goldman N. 2007. Socioeconomic differences in mortality among U.S. adults: Insights into the Hispanic paradox. J Gerontol B Psychol Sci Soc Sci 62:S184-S192.

Warren JR, Kuo HH. 2003. How to measure "what people do for a living" in research on the socioeconomic correlates of health. Ann Epidemiol 13:325-334.

Warren JR, Hoonakker P, Carayon P, Brand J. 2004. Job characteristics as mediators in SES-health relationships. Soc Sci Med 59:1367-1378.

Western B, Bloome D. 2009. Variance function regressions for studying inequality Sociol Methodol 39:293-326.

Williams DR, Yan Y, Jackson JS, Anderson NB. 1997. Racial differences in physical and mental health: Socio-economic status, stress and discrimination. J Health Psychol 2:335-351.

Zimmerman FJ, Christakis DA, Vander Stoep A. 2004. Tinker, tailor, soldier, patient: Work attributes and depression disparities among young adults. Soc Sci Med 58:1889-1901. 